\title{
PENERAPAN BIG DATA PADA FORE $X$ TRADING MENGGUNAKAN ANALISA STATISTIK DENGAN BREAKOUT STRATEGY
}

\author{
Busman $^{1}$, Nurhayati ${ }^{2}$, Fiqi Amali ${ }^{3}$, Zainal Muttaqin ${ }^{4}$ \\ ${ }^{1}$ Jurusan Akuntansi, Fakultas Ekonomi, Universitas Islam Attahiriyah, Jakarta \\ Jln. Melayu Kecil III / 15 Tebet, Jakarta-Selatan \\ 2,3,4 Prodi Teknik Informatika, Fakultas Sains dan Teknologi, UIN Syarif Hidayatullah, Jakarta \\ Jalan Ir. Haji Juanda No. 95 Ciputat , Tangerang Selatan, Banten 15412

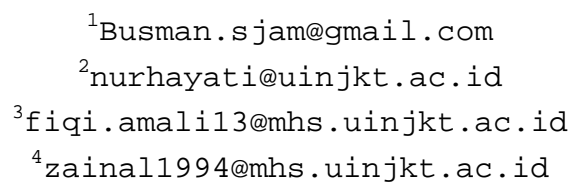

Abstrak: Perdagangan forex merupakan investasi yang berisiko tinggi dan memiliki prospek yang tinggi. Banyaknya kalangan yang berperan di dalamnya dan besarnya nilai uang yang beredar menjadikan pasar forex sulit untuk dikendalikan oleh kalangan tertentu sehingga diperlukan sistem prediksi dalam menetukan kebijakan yang diambil untuk mencapai profit yang tinggi. Pada penelitian ini bertujuan untuk menganalisa potensi break yang terjadi setiap tahunnya berdasarkan data history pada masa lampau. Harga yang selalu bergerak fluktuatif secara tidak langsung memberikan keuntungan bagi para trader yang tepat dalam menganalisa. Selain memprediksi harga yang akan terjadi, terdapat pula proses memprediksi potensi jumlah loss yang terjadi sehingga dapat diminimalisir. Parameter yang digunakan untuk menentukan keputusan buy atau sell adalah berdasarkan input nilai high dan low dari sebuah candlestick. Tingkat keberhasilan prediksi forex menggunakan analisa statistik dengan breakout strategy mampu menghasilkan profit hingga 92\%, tergantung dari nilai lot yang dipertaruhkan.

Kata Kunci: Forex, Brekaout Startegy, high \& low, candlestick

\begin{abstract}
Forex trading is a high risk investment and has high prospects. The number of people who play a role in it and the value of money in circulation makes the forex market is difficult to be controlled by certain circles so it takes the prediction system in determining the policies taken to achieve high profit. In this study aims to analyze the potential breaks that occur each year based on historical data in the past. Price is always moving fluctuate indirectly provide benefits for traders who are appropriate in analyzing. In addition to predicting the price that will occur, there is also the process of predicting the potential number of losses that occur so that can be minimized. The parameters used to determine the buy or sell decision are based on the input of the high and low values of a candlestick. The success rate of forex predictions using statistical analysis with breakout strategy is able to generate profits up to $92 \%$, depending on the lot value at stake
\end{abstract}

Keywords: Forex, Brekaout Startegy, high \& low, candlestick

\section{PENDAHULUAN}

\section{A. Latar Belakang}

Trading Forex atau yang lebih dikenal dengan valas merupakan suatu jenis transaksi yang memperdagangkan mata uang (currency) suatu negara tehadap mata uang negara lainnya dengan tujuan untuk mendapatkan keuntungan (profit) dari perbedaan nilai mata uang. Pasar forex tidak seperti pasar saham, pasar forex bersifat interbank atau Over The Counter karena waktu perdagangannya yang secara kontinyu mengikuti waktu perdagangan masing-masing negara dan bisa diasumsikan bahwa pasar forex buka 24 jam.

Yu Gu (2012) berpendapat dalam perdagangan forex, produk digambarkan sebagai pasangan mata 


\section{Jurnal Pseudocode, Volume IV Nomor 2, September 2017, ISSN 2355-5920 www.ejournal.unib.ac.id/index.php/pseudocode}

uang, dan proses perdagangan adalah menukarkan mata uang yang satu dengan mata uang yang lain. Perdagangan forex mengambil keuntungan dari fluktuasi pasar yang tinggi. Harga suatu mata uang terhadap mata uang lain akan mengalami peningkatan (bulliish) ataupun penurunan (bearish). Selisih antara harga beli dan harga jual adalah keuntungan yang diperoleh pedagang.

Investasi forex online trading merupakan salah satu lahan bisnis yang menggiurkan karena tingkat return-nya sangat tinggi. Di dalam pasar forex, perputaran uang mencapai 3,8 triliun USD setiap harinya. Pergerakan harga yang fluktuatif dan tingkat likuiditas yang tinggi membuat investasi forex menjadi salah satu komoditi yang sangat potensial untuk mendapatkan profit yang besar dan cepat. Namun seperti halnya profit yang dijanjikan, bisnis ini juga mengandung resiko, resiko yang sama besarnya seperti profit yang dijanjikan (Hiqmad M. Pilliangsani, 2012: xiii)

Resiko yang besar itu dapat kita minimalisir dengan cara melakukan analisa terhadap pasar. Analisa adalah kegiatan memperhitungkan, menimbang dan mengukur kejadian atau data masa lalu dan sekarang untuk memprediksi arah pergerakan harga di masa depan. Ada dua jenis analisa yang dikenal dalam dunia trading, yaitu teknikal dan analisa fundamental. Analisis fundamental merupakan analisis yang didasarkanpada situasi dan kondisi ekonomi, politik dan keamanan secara global, sedangkan analisa teknikal lebih menitikberatkan pada pergerakan pasar.

Berdasarkan permasalahan-permasalahan dalam uraian diatas, maka pada tugas akhir ini akan dilakukan analisa teknikal terhadap breakout harga setiap harinya sehingga diketahui nilai yang aman dalam menentukan keputusan kapan waktu tepat untuk masuk ke dalam pasar.

\section{B. Rumusan Masalah \& Pemecahannya}

Permasalahan yang dibahas dalam penelitian ini adalah bagaimana menerapkan big data pada forex online trading menggunakan analisa statistik dengan breakout strategy.

\section{Tujuan Penelitian}

Hal - hal yang ingin dicapai dalam penelitian ini adalah untuk menerapkan big data pada forexonline trading menggunakan analisa statistik dengan breakout strategy.

\section{Manfaat Penelitian}

Manfaat yang didapatkan dalam melakukan penelitian adalah:

1. Menambah wawasan dan pengetahuan peneliti mengenai pasar forex dan potensi bisnis di dalamnya

2. Memberikan wawasan mengenai implementasi konsep Big Data pada forex online trading.

3. Hasil penelitian ini dapat dijadikan referensi untuk pengembangan penelitian selanjutnya sehingga meningkatkan akurasi terhadap prediksi pergerakan harga pasar forex di kemudian hari

\section{E. Batasan Penelitian}

Batasan penelitian untuk penelitian ini adalah sebagai berikut :

1. Analisa harga yang digunakan adalah analisa teknikal dengan Breakout Strategy.

2. Sumber data utama yang digunakan berasal dari server pada broker IC Market.

3. Break harga yang diteliti hanya break low dan high pada timeframe harian. 


\section{Jurnal Pseudocode, Volume IV Nomor 2, September 2017, ISSN 2355-5920}

www.ejournal.unib.ac.id/index.php/pseudocode

4. Pasangan mata uang yang diteliti adalah EU/USD

\section{LANDASAN TEORI}

\section{A. Pasar Forex}

Trading Forex adalah perdagangan mata uang dari negara yang berbeda satu sama lain. Forex ini adalah singkatan dari Foreign Exchange. Sebagai contoh, mata uang yang beredar di Eropa disebut Euro (EUR) dan mata uang yang beredar di Amerika Serikat disebut Dolar AS (USD). Sebuah contoh dari perdagangan Forex adalah untuk membeli Euro dan secara bersamaan menjual US Dolar yang disingkat EUR/USD. Sedangkan pasar Forex adalah pasar tunai non stop dimana terdapat mata uang negara-negara yang diperdagangkan.

Pada Forex, terdapat pair yang di dalamnya terdapat session yang dikenal dengan istilah time frame yang terdiri dari time frame $1 \mathrm{M}$ (per-1menit), 5M (per-5-menit), 15M (per-15-menit), 30M (per-30-menit), H1 (per hours), H4(per-fourhours), D1 (daily), W1 (weekly), dan MN (monthly). Di dalamnya terdapat komponen berupa candlestick yang memiliki variabel waktu, open, high, low, close.

\section{B. Analisa Teknikal}

Analisa teknikal adalah metode analisis yang menitikberatkan pada pergerakan pasar. Metode ini dijalankan dengan cara memperhatikan perubahan harga dan volume perdagangan saham di pasar. Analisis teknikal banyak digunakan oleh dealer sebagai pertimbangan dalam menentukan kapan membeli atau menjual saham (sellor buy decision). (Suharto : 2013)

Analisa teknikal saham bertujuan untuk memprediksi bagaimana permintaan dan pasokan dimasa mendatang, serta menganalisa harga saham yang mungkin akan terbentuk. Para analisis teknikal juga percaya bahwa proses perubahan harga saham yang disebabkan oleh adanya suatu informasi yang baru di pasar akan cenderung mengikuti suatu tren tertentu. (Suharto : 2013)

Analisa teknikal adalah analisa pergerakan yang didasarkan pada hitungan matematis (rumus, grafik, chart, dan sebagainya). Dengan memadukan pergerakan suatu instrumen dengan rumus-rumus matematis tertentu. Dapat memberikan gambaran atau prediksi di masa depan. Yang harus diperhatikan adalah kata-kata gambaran/prediksi, jadi keakuratan tidaklah 100\%. Besarnya keakuratan inilah yang menjadi seni dan level tersendiri dari masing-masing trader. Jika semakin rajin mengasah rumus, mengevaluasi, memadukan, dan sebagainya maka akanmmenjadi lebih presisi. (Suharto : 2013)

\section{Breakout Strategy}

Breakout adalah strategi yang berlawanan dengan apa yang kita pahami secara umum. Kita tidak membeli di titik terendah lalu menjual di titik tertinggi. Yang dilakukan adalah membeli di atas titik tertinggi (titik resisten) dan menjual di bawah titik terendah (titik support).Strategi breakout diterapkan ketika muncul tren yang kuat ditambah dengan kondisi pasar yang sedang bergejolak. Tren yang kuat, khususnya, cenderung mampu menembus harga.

Dalam tren pasar yang berkembang, semua orang akan berlomba-lomba melakukan pembelian ketika harga bergerak naik. Strategi breakout adalah menunggu pasar mencapai titik resisten lalu masuk (break) diatas titik (out) tersebut. Dalam tren yang berkembang, biasanya tidak lama pasar 
Jurnal Pseudocode, Volume IV Nomor 2, September 2017, ISSN 2355-5920 www.ejournal.unib.ac.id/index.php/pseudocode

akan bergerak ke titik yang lebih tinggi lagi. (Suharto : 2013)

\section{Metodologi Dan PeRANCANGAN Sistem}

\section{A. Gambaran Umum Perangkat Sistem}

Aplikasi perangkat analisa forex trading merupakan implementasi dari analisa teknikal dengan breakout strategy. Pada aplikasi ini terdapat dua proses utama yaitu proses perancangan data training dan proses pengambilan keputusan. Proses perancangan data training yaitu dengan menghitung seluruh nilai breakout yang terjadi dalam rentang setahun dalam timeframeH1, kemudian didapatkan nilai minimal breakout yang yang kita jadikan acuan tiap harinya. Penghitungan itu juga menghasilkan nilai stoploss untuk meminimalisir nilai breakout yang tidak menecapai nilai breakout acuan.

\section{B. Perancangan Perangkat Lunak}

Proses - proses untuk perancangan model prediksi trend saham adalah :

1. Memasukkan data history untuk dianalisa.

2. Perhitungan selisih nilai high dan low pada breakout yang terjadi.

3. Menentukan nilai potensi break yang akan terjadi (pips).

4. Mengatur posisi stoploss untuk meminimalisir kerugian.

5. Hasil prediksi (output).

\section{HASIL DAN PEMBAHASAN}

A. Nilai Breakout Time Frame D1

Tabel 1. Hasil Uji Evaluasi Breakout H1 EUUSD tahun 2015

\begin{tabular}{|llllll|}
\hline 0 & 1 & 1 & 1 & 2 & 4 \\
5 & 5 & 5 & 6 & 6 & 8 \\
8 & 8 & 8 & 9 & 10 & 10 \\
10 & 10 & 10 & 10 & 11 & 11 \\
\hline
\end{tabular}

\begin{tabular}{|c|c|c|c|c|c|}
\hline 11 & 11 & 11 & 12 & 12 & 14 \\
\hline 14 & 14 & 14 & 15 & 15 & 15 \\
\hline 15 & 15 & 16 & 16 & 16 & 16 \\
\hline 16 & 16 & 16 & 17 & 17 & 17 \\
\hline 18 & 18 & 19 & 20 & 20 & 20 \\
\hline 20 & 21 & 22 & 22 & 22 & 23 \\
\hline 23 & 24 & 25 & 25 & 25 & 26 \\
\hline 26 & 27 & 27 & 27 & 27 & 28 \\
\hline 28 & 29 & 29 & 29 & 29 & 30 \\
\hline 31 & 31 & 31 & 31 & 32 & 32 \\
\hline 32 & 32 & 32 & 34 & 34 & 34 \\
\hline 34 & 35 & 36 & 37 & 37 & 37 \\
\hline 38 & 39 & 39 & 39 & 39 & 39 \\
\hline 40 & 40 & 40 & 41 & 42 & 42 \\
\hline 42 & 42 & 43 & 43 & 44 & 44 \\
\hline 44 & 45 & 45 & 45 & 46 & 47 \\
\hline 47 & 47 & 48 & 48 & 48 & 49 \\
\hline 49 & 51 & 52 & 52 & 52 & 52 \\
\hline 54 & 54 & 54 & 55 & 55 & 55 \\
\hline 56 & 56 & 57 & 58 & 58 & 59 \\
\hline 60 & 61 & 62 & 62 & 63 & 64 \\
\hline 64 & 64 & 64 & 68 & 69 & 70 \\
\hline 70 & 71 & 73 & 74 & 74 & 75 \\
\hline 76 & 77 & 77 & 78 & 78 & 78 \\
\hline 79 & 79 & 82 & 83 & 86 & 87 \\
\hline 88 & 89 & 89 & 89 & 91 & 92 \\
\hline 92 & 93 & 95 & 96 & 97 & 99 \\
\hline 104 & 104 & 105 & 105 & 106 & \\
\hline 108 & 110 & 111 & 115 & 120 & \\
\hline 122 & 125 & 125 & 126 & 127 & \\
\hline 128 & 130 & 130 & 133 & 134 & \\
\hline 140 & 144 & 147 & 148 & 152 & \\
\hline 160 & 172 & 173 & 176 & 180 & \\
\hline 182 & 198 & 202 & 205 & 225 & \\
\hline 233 & 324 & 345 & 391 & & \\
\hline
\end{tabular}


Jurnal Pseudocode, Volume IV Nomor 2, September 2017, ISSN 2355-5920 www.ejournal.unib.ac.id/index.php/pseudocode

B. Nilai Floating Sebagai Acuan Stoploss

Tabel 2. Nilai float pada break $<8$ pips

\begin{tabular}{|c|c|c|c|}
\hline $\begin{array}{c}\text { Nilai } \\
\text { Stoploss }\end{array}$ & $\begin{array}{c}\text { Jumlah } \\
\text { Pips } \\
\text { didapat }\end{array}$ & $\begin{array}{c}\text { Jumlah } \\
\text { Pips } \\
\text { yang } \\
\text { hilang }\end{array}$ & $\begin{array}{c}\text { Total } \\
\text { Pips } \\
\text { didapat } \\
\text { (setahu } \\
\text { n) }\end{array}$ \\
\hline 65 & 1080 & 594 & 486 \\
\hline 68 & 1085 & 552 & 533 \\
\hline 69 & 1090 & 490 & 600 \\
\hline 74 & 1095 & 450 & 645 \\
\hline 79 & 1100 & 400 & 700 \\
\hline 83 & 1105 & 336 & 769 \\
\hline 94 & 1110 & 285 & 825 \\
\hline 172 & 1115 & 346 & 769 \\
\hline 321 & 1120 & 322 & 798 \\
\hline
\end{tabular}

\section{Prediksi Profit yang Mampu Dicapai}

Tabel 3. Tabel potensi profit dalam setahun

\begin{tabular}{|c|c|c|c|}
\hline $\begin{array}{c}\text { Nilai } \\
\text { Stoploss }\end{array}$ & $\begin{array}{c}\text { Jumlah } \\
\text { Pips } \\
\text { didapat }\end{array}$ & $\begin{array}{c}\text { Jumlah } \\
\text { Pips } \\
\text { yang } \\
\text { hilang }\end{array}$ & $\begin{array}{c}\text { Total } \\
\text { Pips } \\
\text { didapat } \\
\text { (setahun) }\end{array}$ \\
\hline 65 & 1080 & 594 & 486 \\
\hline 68 & 1085 & 552 & 533 \\
\hline 69 & 1090 & 490 & 600 \\
\hline 74 & 1095 & 450 & 645 \\
\hline 79 & 1100 & 400 & 700 \\
\hline 83 & 1105 & 336 & 769 \\
\hline 94 & 1110 & 285 & 825 \\
\hline 172 & 1115 & 346 & 769 \\
\hline 321 & 1120 & 322 & 798 \\
\hline
\end{tabular}

\section{Implementasi Sistem ke Dalam Pasar Forex}

Pada analisa sebelumnya, di dapat bahwa nilai take profit yang disarankan sebesar 8 pips, serta stop loss yang paling kecil mengalami kerugian adalah dengan nilai 95 pips. Jika analisa itu diterapkan ke pasar di bulan Januari hingga Februari, maka hasilnya adalah semua transaksi yang terjadi tertutup dalam keadaan take profit

Tabel 4. Tabel harga pada timeframe D1 bulan Januari-Februari 2016

\begin{tabular}{|c|c|c|c|c|c|c|}
\hline Tanggal & High & Low & $\begin{array}{c}\text { Break } \\
\text { High }\end{array}$ & $\begin{array}{c}\text { Nilai } \\
\text { Break }\end{array}$ & $\begin{array}{c}\text { Break } \\
\text { Low }\end{array}$ & $\begin{array}{c}\text { Nilai } \\
\text { Break }\end{array}$ \\
\hline 2016.01 .04 & 1,09464 & 1,07812 & High & 9,3 & Low & 60,5 \\
\hline 2016.01 .05 & 1,08388 & 1,07107 & - & - & Low & 70,5 \\
\hline 2016.01 .06 & 1,07995 & 1,07149 & - & - & - & - \\
\hline 2016.01 .07 & 1,09401 & 1,07711 & High & 140,6 & - & - \\
\hline 2016.01 .08 & 1,09335 & 1,08034 & - & - & - & - \\
\hline 2016.01 .11 & 1,09693 & 1,08481 & High & 35,8 & - & - \\
\hline 2016.01 .12 & 1,09003 & 1,08198 & - & - & Low & 28,3 \\
\hline 2016.01 .13 & 1,08877 & 1,08050 & - & - & Low & 14,8 \\
\hline 2016.01 .14 & 1,09431 & 1,08347 & High & 55,4 & - & - \\
\hline 2016.01 .15 & 1,09846 & 1,08547 & High & 41,5 & - & - \\
\hline 2016.01 .18 & 1,09275 & 1,08689 & - & - & - & - \\
\hline 2016.01 .19 & 1,09391 & 1,08595 & High & 11,6 & Low & 9,4 \\
\hline
\end{tabular}


Jurnal Pseudocode, Volume IV Nomor 2, September 2017, ISSN 2355-5920 www.ejournal.unib.ac.id/index.php/pseudocode

\begin{tabular}{|c|c|c|c|c|c|c|}
\hline 2016.01.20 & 1,09759 & 1,08773 & High & 36,8 & - & - \\
\hline 2016.01.21 & 1,09211 & 1,07777 & - & - & Low & 99,6 \\
\hline 2016.01 .22 & 1,08766 & 1,07891 & - & - & - & - \\
\hline 2016.01.25 & 1,08569 & 1,07876 & - & - & Low & 1,5 \\
\hline 2016.01.26 & 1,08744 & 1,08186 & High & 17,5 & - & - \\
\hline 2016.01.27 & 1,09164 & 1,08507 & High & 42 & - & - \\
\hline 2016.01.28 & 1,09677 & 1,08697 & High & 51,3 & - & - \\
\hline 2016.01.29 & 1,09486 & 1,08099 & - & - & Low & 59,8 \\
\hline 2016.02.01 & 1,09128 & 1,08149 & - & - & - & - \\
\hline 2016.02.02 & 1,09399 & 1,08854 & High & 27,1 & - & - \\
\hline 2016.02.03 & 1,11456 & 1,09038 & High & 205,7 & - & - \\
\hline 2016.02.04 & 1,12391 & 1,10697 & High & 93,5 & - & - \\
\hline 2016.02.05 & 1,12454 & 1,11090 & High & 6,3 & - & - \\
\hline 2016.02.08 & 1,12157 & 1,10867 & - & - & Low & 22,3 \\
\hline 2016.02.09 & 1,13381 & 1,11625 & High & 122,4 & - & - \\
\hline 2016.02.10 & 1,13114 & 1,11607 & - & - & Low & 11,8 \\
\hline 2016.02.11 & 1,13764 & 1,12741 & High & 65 & - & - \\
\hline 2016.02.12 & 1,13337 & 1,12141 & - & - & Low & 60 \\
\hline 2016.02.15 & 1,12499 & 1,11279 & - & - & Low & 86,2 \\
\hline 2016.02.16 & 1,11928 & 1,11242 & - & - & Low & 3,7 \\
\hline 2016.02.17 & 1,11790 & 1,11059 & - & - & Low & 18,3 \\
\hline 2016.02.18 & 1,11497 & 1,10709 & - & - & Low & 35 \\
\hline 2016.02.19 & 1,11393 & 1,10667 & - & - & Low & 4,2 \\
\hline 2016.02.22 & 1,11248 & 1,10032 & - & - & Low & 63,5 \\
\hline 2016.02.23 & 1,10528 & 1,09901 & - & - & Low & 13,1 \\
\hline 2016.02.24 & 1,10465 & 1,09572 & - & - & Low & 32,9 \\
\hline 2016.02.25 & 1,10501 & 1,09868 & High & 3,6 & - & - \\
\hline 2016.02.26 & 1,10684 & 1,09117 & High & 18,3 & Low & 75,1 \\
\hline 2016.02.29 & 1,09626 & 1,08592 & - & - & Low & 52,5 \\
\hline
\end{tabular}

\section{KESIMPULAN \& SARAN}

\section{A. Kesimpulan}

Setelah dilakukan pengujian terhadap sistem, maka dapat diambil beberapa kesimpulan sebagai berikut :

1. Pada timeframe D1, sistem mampu menghasilkan profit konsisten selama 2 bulan.

2. Memperkecil nilai stoploss tidak otomatis memperkecil loss yang dialami, perlu sebuah perhitungan matang untuk menentukan stop loss yang tepat.

3. Secara keseluruhan, order selalu tertutup dalam keadaan taking profit namun tertutupnya order tidak selalu di hari yang sama dengan waktu dibukanya order.

\section{B. Saran}

1. Perhitungan masih dilakukan hanya dalam rentang setahun, sebaiknya rentang ini diperlebar untuk meningkatkan akurasi sistem. 


\section{Jurnal Pseudocode, Volume IV Nomor 2, September 2017, ISSN 2355-5920 www.ejournal.unib.ac.id/index.php/pseudocode}

2. Pair yang dianalisa hanya pair EUUSD, padahal masih banyak pair lainnya yang berpotensi memiliki nilai break yang lebih besar untuk mendapatkan hasil yang lebih besar.

\section{REFERENSI}

[1] Alqodri, Febrianto, Suci Lestari, dan Nanscy Ev Wardani. 2015. Teknologi Trading Berbasis Expert Advisor (EA) pada Pasar Valuta Asing dengan Teknik Kalender Ekonomi. Semnas Teknomedia Online 3.1: 512.

[2] Anonim. 2013. http://www.nusaforex.com/belajarforex/nubitol/pip-spread-dan-profit diakses tanggal 09 Januari 2016 pukul 15.12

[3] FBSTeam. 2016. https://idnfbs.com/about diakses tanggal 10 Januari 2016 pukul 19.32.

[4] Hadi, Anthony, Murtiyanto Santoso, Resmana Lim. 2013. Pembuatan Market Expert Advisor pada Currency Market Menggunakan Fibonacci, Stochastic dan MACD Indicator. Jurnal Dimensi Teknik Elektro Universitas Kristen Petra Vol. 1, No. 1, (2013) 55-60.
[5] Hartanto, Eka. 2013. “Otomatisasi Forex Online Trading Dengan Membangun dan Mengimplementasikan Pola Aplikasi MQL4 Denngan Bahasa C”. Skripsi Universitas Dian Nuswantoro, Semarang.

[6] Hermawati, Fajar Astuti. 2014. Data Mining. Yogyakarta : Andi Publisher.

[7] Pilliangsani, Hiqmad M. 2012. Hindari 5 Kesalahan Mainkan 5 Strategi Profit. Jakarta : Elex Media Komputindo.

[8] Santoso, Heri. 2012. Cara Mudah Membuat Robot Trading Profitable dengan EA Martiagle dan EA Scalping. Jakarta : Elex Media Komputindo.

[9] Suharto, Frento T. MM, MBA. 2013. Mengungkap Rahasia Forex. Jakarta : Elex Media Komputindo.

[10] Sutanto, Taufik. 2015. "Tipe Data di Statistika (Data Mining/Science)”. http://sutanto.org/model-statistikadata-science/ (diakses tanggal 09 Januari 2016 pukul 20.05)

[11] Prasetyo, Eko. 2013. Data Mining : Konsep dan Aplikasi Menggunakan Matlab. Yogyakarta : Andi Publisher.

[12] Widodo, Prabowo Pudjo, Rahmadya Trias Hendayanto, Herlawati. 2013. Penerapan Data Mining Dengan Matlab. Bandung : Rekayasa Sains.

[13] Wirdhaningsih, Kurnia Putri, Dian Eka Ratnawati, S.Si., Drs. Marji, MT. 2013. Penerapan Algoritma Decision Tree C5.0 untuk Peramalan Forex. Jurnal Universitas Brawijaya Malang 